\title{
Growth of small follicles and concentrations of FSH during the equine oestrous cycle
}

\author{
O. J. Ginther and D. R. Bergfelt \\ Department of Animal Health and Biomedical Sciences, Veterinary Science Building, University of \\ Wisconsin-Madison, Madison, WI 53706, USA
}

The temporal associations between increases in FSH and growth of small follicles (2-20 mm) were studied during one oestrous cycle (ovulation to ovulation) in 15 horse mares. Follicular diameters were obtained ultrasonically. For each day, follicles were combined for both ovaries, grouped from largest to smallest (excluding dominant follicles), and divided into three to five tiers of six follicles for each mare (for example: tier 1, six largest follicles; tier 2, next six largest follicles). A significant increase in mean diameters followed by a significant decrease was used to define a follicular wave within each of the tiers for each mare. Day of wave emergence was defined by the lowest mean preceding the increase. Follicular waves were detected in all tiers in each mare. The number of detected waves per interovulatory interval was greater $(P<0.05)$ for tier $5(2.8 \pm 0.4)$ than for tier $1(1.1 \pm 0.1)$ and tier 2 $(1.9 \pm 0.3)$. A primary follicular wave (wave giving rise to the dominant follicle that ovulated during the subsequent oestrus) was identified in tier 1 in all mares. Composite profiles were constructed by normalizing each tier for each mare to the mean day of emergence of the primary wave for all mares, as detected in tier 1 . The composite follicular profiles for the five tiers were approximately parallel; the follicles for tiers $2-5$ emerged on the mean day of emergence of the primary wave ( 6 days after ovulation). The range of follicular means on the common day of wave emergence was $3 \mathrm{~mm}$ (tier 5) to $12 \mathrm{~mm}$ (tier 1). The follicles of tier 1 on the day of emergence of the primary wave would have been $3 \mathrm{~mm}$ before ovulation, if the rate of growth before emergence was similar to the rate after emergence. The common day of emergence for each of the five composite tiers was temporally associated with the highest $(P<0.05)$ mean FSH concentrations of the oestrous cycle. In another analysis, which did not use the tiering procedure, a temporal association between increased exposure to FSH and growth of $2-3 \mathrm{~mm}$ follicles was suggested by a higher $(P<0.05)$ frequency of increased FSH concentrations than of decreased concentrations on the days of increased numbers of 2-3 mm follicles.

\section{Introduction}

During the equine oestrous cycle (mean duration: 22 days) the follicles of major follicular waves (waves that develop a dominant follicle) diverge in diameter after growth for about one week beyond $12 \mathrm{~mm}$; one follicle (dominant follicle) continues to grow and reaches a large diameter (about $35 \mathrm{~mm}$ ), whereas the remaining follicles regress (Ginther, 1992, 1993). Major waves may be subdivided into primary and secondary waves. Primary waves emerge during mid-dioestrus and the dominant follicle terminates in the primary ovulation (ovulation associated with oestrus). Secondary waves emerge during late oestrus or early dioestrus and give rise to a dominant follicle that ovulates (dioestrous ovulation) or regresses. Recently, a technique was developed for ultrasonic characterization of follicular waves without maintaining the identity of individual follicles in mares (Ginther and Bergfelt, 1992). This approach has

Received 13 October 1992. been used to confirm the existence of primary and secondary major waves and to demonstrate the occurrence of minor waves (follicular waves that do not give rise to a dominant follicle; Ginther, 1993). A follicular wave (major or minor) was defined as a significant increase followed by a significant decrease in diameters of the six largest follicles, excluding the dominant follicle after it became distinguishable by its large size. The diameters of follicles that were characterized were approximately $10-20 \mathrm{~mm}$. Little is known about the dynamics of smaller follicles. Studies of excised ovaries (Pineda et al., 1973; Driancourt et al., 1982), confirmed by ultrasound studies (Pierson and Ginther, 1987), indicated that increased follicular activity of smaller follicles (for example $2-5 \mathrm{~mm}$ ) can occur during early dioestrus. However, it is not known how the activity of small follicles relates to the emergence of major waves, as detected in the studies of larger follicles. An association between circulating concentrations of FSH and follicular development in mares has been suggested in several reports (for review see Ginther, 1992). An increase in mean concentrations 
of FSH was shown to begin a few days before the dominant follicle of a primary follicular wave reached $15 \mathrm{~mm}$ (Bergfelt and Ginther, 1993).

The present study considered the nature of the dynamics of small follicles during the oestrous cycle and the relationship of growth of small follicles to circulating concentrations of FSH and to the emergence of major follicular waves.

\section{Materials and Methods}

\section{Animals}

Fifteen mares were studied daily for one interovulatory interval (interval from ovulation associated with one oestrus to ovulation associated with the next oestrus). The first interovulatory interval of the ovulatory season was not used. The mares appeared to be primarily Quarter horses based on body conformation, were nonlactating, and were kept under natural daylength. Reproductive histories were not known, but animals were 3-17 years old. Care and management were as described by Pierson and Ginther (1987).

The data used in the study reported here were collected during a previous study of follicular population dynamics during the oestrous cycle in 40 mares (Pierson and Ginther, 1987). In the previous study, follicular diameters were recorded daily for all follicles $\geq 2 \mathrm{~mm}$ detected by transrectal ultrasonography. Follicles were categorized according to diameter and population changes were based on numbers in the various categories averaged over all mares for each day. Follicular waves were not characterized and FSH concentrations were not determined. However, daily blood samples had been collected for possible future use from 15 mares throughout an interovulatory interval. In the present study, follicular data were used for the $\mathbf{1 5}$ mares from which daily blood samples had been collected.

\section{Follicular evaluation in individual mares}

Initially, diameters of the three largest follicles (regardless of day-to-day identity) per ovary were profiled for the interovulatory interval (Fig. 1), as described by Ginther (1993). From these profiles, dominant follicles could be identified, and diameters of dominant follicles during their periods of identity were excluded before identifying follicular waves. For each day and each mare, the follicles were combined for both ovaries (excluding dominant follicles) and were ranked from largest to smallest without regard to the day-to-day identity of individual follicles. The follicles were then divided into tiers of six follicles per tier (for example tier 1 , six largest follicles; tier 2, next six largest follicles); six follicles were used per tier because this was the minimal number that showed significant changes in mean diameter consistently for all major waves (Ginther and Bergfelt, 1992). Only tiers with complete data (six follicles for each day) were used, except that the tier with the smallest follicles was accepted if missing data were scattered and did not exceed $7 \%$ of the observations. From these criteria, the number of tiers was three (two mares), four (three mares), and five (ten mares). In addition, four mares had six tiers, and the sixth tier was not studied.

The follicles of tier 1 were evaluated for each mare, as described by Ginther and Bergfelt (1992). Analyses of variance for sequential data were used followed by the Tukey's multiple range test to locate days of significant $(P<0.05)$ increases and decreases in mean diameters. A follicular wave was identified by a significant increase followed by a significant decrease. The day of emergence of each wave was defined as the lowest follicular mean preceding the significant increase. An identified follicular wave in tier 1 was further defined as major (primary and secondary) if it gave rise to an apparent dominant follicle and minor if it did not. The follicles of tiers $2-5$ were similarly analysed for each tier and mare. However, identified waves were defined as underlying waves because wave-like activity in tiers $2-5$ was not always temporally associated with the waves in tier 1 . The proportion of mares in which an underlying wave emerged on the same day as the primary wave was compared among tiers by $\chi^{2}$ analysis. A follicular wave in one tier that began within one day of a wave in another tier was considered as one follicular wave.

The interovulatory intervals were divided into luteal and follicular phases by the extent of endometrial oedema, as determined by ultrasonic echotexture (Ginther, 1986). The interval from emergence of a wave to the emergence of the next wave was defined as the interwave interval. Number of follicular waves and duration of interwave intervals were compared between luteal and follicular phases by analyses of variance for sequential data. In addition, mares with underlying follicular waves in any of tiers 2-5 emerging between the day of ovulation and the day of emergence of the primary wave were compared with mares without underlying waves during this time by one-way analyses of variance. End points were number of follicles $>5 \mathrm{~mm}$ and mean diameters of follicles of tier 1 on the day of ovulation and on the day of wave emergence.

\section{FSH assay}

Blood samples were drawn by jugular venepuncture into heparinized tubes and immediately put on ice for transportation to the laboratory. After centrifugation, plasma was collected and aliquots were made and stored frozen $\left(-20^{\circ} \mathrm{C}\right)$. Circulating concentrations of FSH were measured in plasma samples using a heterologous radioimmunoassay previously validated in this laboratory (Freedman et al., 1979). The intra- and interassay coefficients of variation were $3.3 \%$ and $14.3 \%$, respectively.

\section{Follicular and FSH evaluation for composite data}

The follicular associations among tiers and the temporal associations between the profiles of follicular tiers and FSH concentrations were studied by averaging over all mares. For each mare, the mean daily follicular values for each of tiers $1-5$ and the FSH concentrations were normalized to a common reference point for all mares. The reference point was the mean day of emergence of the primary wave ( 6 days after ovulation). The resulting composite data were examined separately for each tier by analysis of variance for sequential data followed by Tukey's 


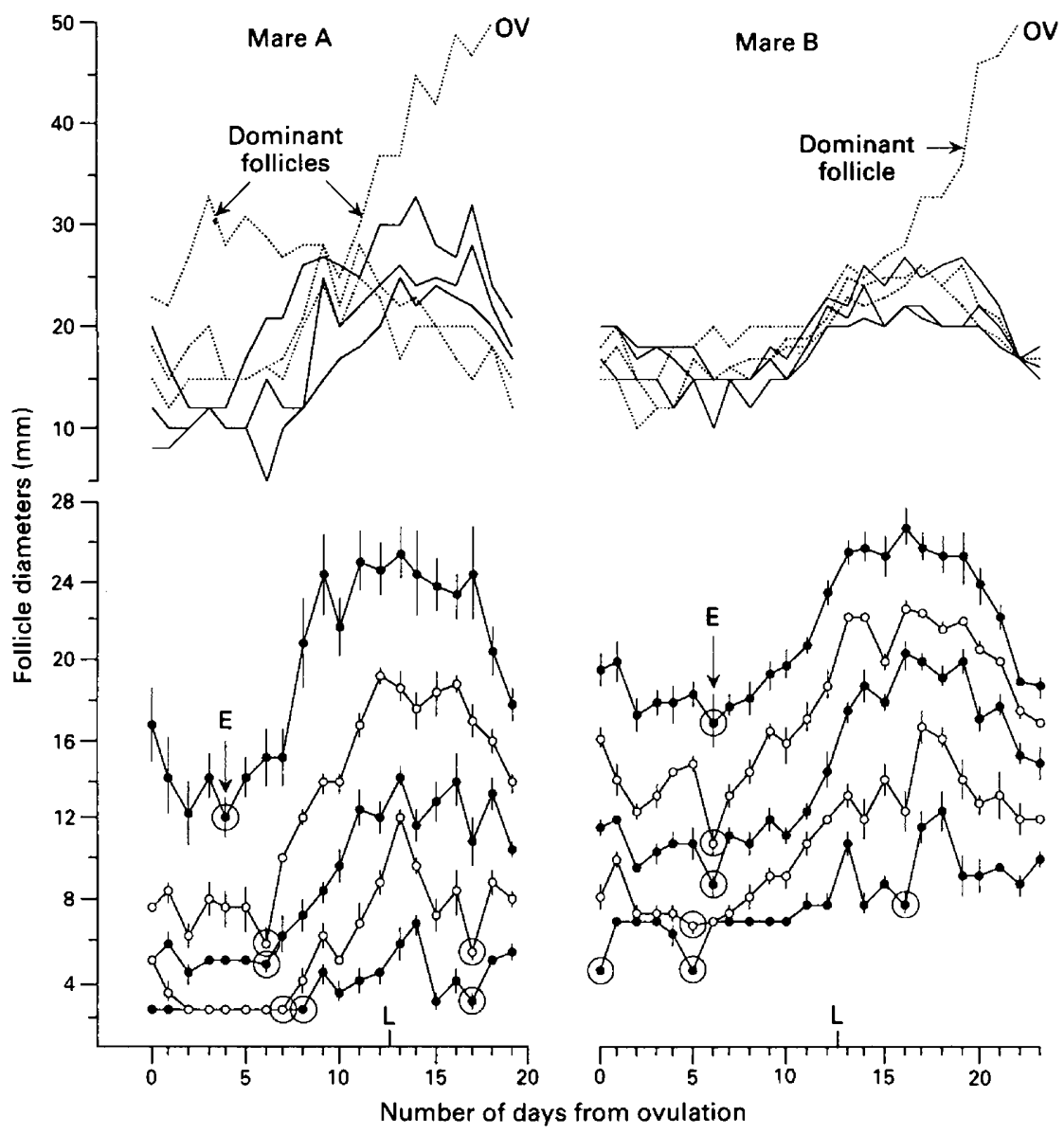

Fig. 1. Diameter profiles of three largest follicles per ovary (upper panel; solid lines = left ovary; dotted lines = right ovary) and mean ( \pm SEM) diameters of the six follicles in each tier (lower panel) for two individual mares. The lowest mean before a significant increase followed by a significant decrease in diameter of follicles is circled to indicate the emergence of a wave. The millimetre scale is expanded for the follicular means of tiers. E: emergence of the primary wave (wave giving rise to the ovulatory follicle); L: luteolysis or day of separation into luteal and follicular phases based on ultrasonic endometrial echotexture.

multiple range test, as described above for individual mares. In addition, the rate of decrease and increase in changes in mean diameters for 6 days before and 6 days after emergence of the primary wave was evaluated by linear regression.

\section{FSH concentration and number of 2-3 mm follicles}

The concentrations of FSH associated with a day-to-day increase in number of $2-3 \mathrm{~mm}$ follicles, including those remaining after construction of the tiers, were examined for the luteal phase and for the follicular phase. For this purpose, only an increase of more than two follicles from one day to the next was used; this was done to reduce the experimental error associated with counting small follicles. The number of events (increase in number of follicles) that was associated with an increase in FSH concentrations on the same 2 days was compared by $\chi^{2}$ analysis to the number of events associated with an FSH decrease. This statistical approach was used because of the large variations in changes in FSH concentrations.

\section{Results}

\section{Individual mares}

All of the 15 mares had a primary follicular wave, and it emerged on a mean of 6 days after ovulation (range: 4-11 days) when the diameter of follicles of tier 1 averaged $11.6 \mathrm{~mm}$ ( \pm 0.5 ; SEM). Maximum diameter reached by the dominant follicle of the primary wave ranged from 36 to $53 \mathrm{~mm}$. Three mares also had secondary waves as indicated by the presence of a large follicle (maximum diameters: 34,35 and $37 \mathrm{~mm}$ ) during early dioestrus (e.g. Fig. 1, Mare A); however, the secondary waves apparently emerged before the first ovulation. The dominant follicles of the secondary waves regressed (two mares) or ovulated (one mare). In two mares, minor waves were detected 10 days and 17 days after ovulation; the maximum diameter attained by the largest follicle was 24 and $20 \mathrm{~mm}$, respectively.

At least one underlying wave (tiers 2-5) was detected in each follicular tier for every mare. In individual mares, emergence 
Table 1. Mean ( $\pm S E M)$ number of follicular waves and number of mares in which emergence of an underlying follicular wave (tiers $2,3,4,5$ ) occurred on the same day as emergence of the primary wave (tier 1 )

\begin{tabular}{lcccc}
\hline Tier & $\begin{array}{c}\text { Number } \\
\text { of } \\
\text { mares }\end{array}$ & $\begin{array}{c}\text { Number of } \\
\text { waves/mare }\end{array}$ & $\begin{array}{c}\text { Mean follicular } \\
\text { diameter on } \\
\text { day of emergence } \\
\text { of primary wave } \\
(\mathrm{mm})\end{array}$ & $\begin{array}{c}\text { Number of mares } \\
\text { with emergence of } \\
\text { an underlying wave } \\
\text { on same day as } \\
\text { emergence of primary wave }\end{array}$ \\
\hline 1 & 15 & $1.1 \pm 0.1$ & $11.6 \pm 0.5$ & - \\
2 & 15 & $1.9 \pm 0.3$ & $7.5 \pm 0.5$ & $10(67 \%)$ \\
3 & 15 & $2.3 \pm 0.3$ & $5.3 \pm 0.4$ & $6(40 \%)$ \\
4 & 13 & $2.1 \pm 0.2$ & $3.8 \pm 0.3$ & $2(8 \%)$ \\
5 & 10 & $2.8 \pm 0.3$ & $2.8 \pm 0.2$ & - \\
Overall & 15 & $4.4 \pm 0.4$ & - & $20.3)$ \\
\hline
\end{tabular}

aSignificant difference $(P<0.01)$ among tiers.

bSignificant difference $(P<0.05)$ in ratios for tiers 2 and 3 versus tiers 4 and 5.

'When emergence of a wave, including the primary wave, of one tier began within one day of emergence of a wave for another tier, the waves were counted as one wave.

of an underlying wave on the same day as emergence of the primary wave (tier 1$)$ occurred more often $(P<0.05)$ for tiers 2 and $3(53 \%)$ than for tiers 4 and $5(13 \%$; Table 1$)$. The number of underlying waves was smaller $(P<0.01)$ for tier 2 than for tier 5 , and tiers 3 and 4 were intermediate (Table 1 ). The mean number of follicular waves (waves in adjacent tiers occurring on the same or adjacent days) during the interovulatory interval was $4.4 \pm 0.4$. The mean interwave interval was greater $(P<0.01)$ for the transitional period that overlapped the ending of the luteal phase and the beginning of the follicular phase $(5.9 \pm 0.7$ days $)$ than for the luteal phase $(3.1 \pm 0.3)$ and follicular phase $(3.3 \pm 0.6)$. During the interval from the ovulation at the beginning of the interovulatory interval to emergence of the primary wave, seven mares had underlying waves and eight did not. Mares with detected underlying waves, compared with those without underlying waves, had more $(P<0.05)$ follicles $>5 \mathrm{~mm}$ (13.8 \pm 1.4 versus $8.6 \pm 1.5)$ and greater $(P<0.05)$ mean follicular diameter in tier $1(12.7 \pm 0.7 \mathrm{~mm}$ versus $10.5 \pm 0.6 \mathrm{~mm})$ on the day of emergence of the primary wave. There was no difference in number of follicles or mean follicular diameter on the day of ovulation between the two groups.

\section{Composite data}

The follicular and FSH associations averaged over all mares and normalized to the mean day of emergence of the primary waves (Fig. 2) are shown. There was a significant effect of day for follicle diameters in each tier and for FSH concentrations. Only one day of wave emergence was detected for each of the composite tiers, and the day of emergence occurred on the same day for all tiers ( 6 days after ovulation). The mean concentrations of FSH in the composite data were maximal on days $-1,0$ and 1 relative to the common day of wave emergence for each tier.

\section{FSH concentrations and number of $2-3 \mathrm{~mm}$ follicles}

During the luteal phase, the number of events in which an increase in the number of $2-3 \mathrm{~mm}$ follicles was associated with an increase in FSH concentrations (32 events) was greater $(P<0.02)$ than the number of events associated with a decrease in FSH concentrations (16 events). Most (63\%) of the increases in FSH concentrations were followed by a decrease after one day. Changes in FSH concentrations in association with increases in number of the smallest detected follicles did not occur during the follicular phase.

\section{Discussion}

Often only one major wave emerges during the equine oestrous cycle - the primary wave leading to the ovulation associated with oestrus (Ginther, 1992). This was the predominant pattern found in this study and is a common pattern for this breed (primarily Quarter horses). In some mares and some breeds, especially during the early ovulatory season, modifications may occur, including development of a secondary major wave in early dioestrus or minor waves (no dominant follicle) at any time during the oestrous cycle (Ginther, 1993). In the present study, a primary wave was detected in each mare, but only three mares had a secondary wave and two mares had a minor wave according to the analyses of tier 1 follicles. These results for tier 1 are similar to those of Ginther (1993) for the equine oestrous cycle, which considered only the six largest follicles (equivalent to tier 1). In the previous study, maximum diameter attained by the largest follicle of each wave was ranked from largest to smallest for all identified waves. The greatest discontinuity in the decreasing diameters occurred between 34 and $28 \mathrm{~mm}$ (four standard deviations greater than the mean difference between adjacent values). On this basis, the waves were grouped into major (dominant follicle: $34-56 \mathrm{~mm}$ ) and minor 

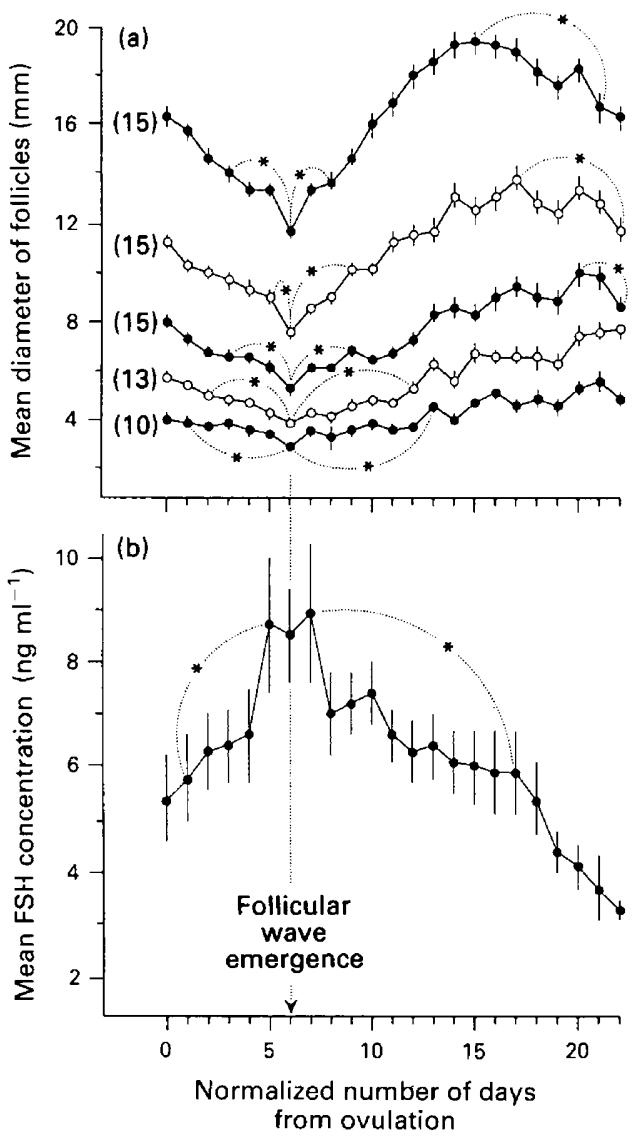

Fig. 2. Composite data showing (a) mean ( \pm SEM) diameters for the follicles of each follicular tier and (b) mean daily FSH concentrations. Data for follicular tiers and FSH concentrations for the 15 mares were normalized to 6 days after ovulation, the mean day of emergence of the primary wave. For each mare, the daily follicular means for each of tiers 2-5 and the FSH concentrations were normalized with the means for tier 1 . "Significant difference $(P<0.05)$ between the indicated days. Numbers in parentheses are the numbers of mares.

(largest follicle: $19-28 \mathrm{~mm}$ ). These ranges encompassed the major and minor waves of the present data.

The mean day of emergence of the primary wave was 6 days after ovulation when the follicles of tier 1 were approximately $12 \mathrm{~mm}$ (range of means for 15 mares: $8.4-15.0 \mathrm{~mm}$ ). Day of emergence was defined as the lowest value preceding a significant increase in diameter and can be assumed to represent the day before the diameters of growing follicles of the new wave exceeded the diameters of regressing follicles from a previous wave. The identity of the individual follicles from day-today was not determined. Nevertheless, a significant increase followed by a significant decrease in mean diameters of the follicles of tier 1 (six largest follicles, excluding dominant follicles) can be assumed to involve follicular growth and regression, respectively; an individual follicle could move in the opposite direction without loss of significance. On the basis of the results of experiments in which individual follicles were monitored (Sirois et al., 1989; Ginther, 1990; Bergfelt and Ginther, 1993), it is unlikely that a significant increase in diameters of follicles in tier 1 could be a reflection of rapid growth and regression of individual follicles with successive follicles reaching progressively greater diameters. These were the bases of identification and characterization of major and minor follicular waves in the previous study (Ginther, 1993).

The rate of growth (increasing mean diameters) in tier 1 after emergence of the primary wave was approximately twice as fast as the rate of regression (decreasing means) before the emergence of the primary wave $\left(1.02 \mathrm{~mm}\right.$ day $^{-1}$ versus $0.56 \mathrm{~mm}$ day $\left.^{-1}\right)$. This finding agrees with reports that the ovaries contained more atretic than nonatretic follicles (Driancourt et al., 1982) and that the growth rate of follicles $\geq 10 \mathrm{~mm}$ exceeded the regression rate (Palmer, 1987). The growth rates in the present analyses, however, were lower than the estimates based on ultrasonic monitoring of individual follicles $\geq 10 \mathrm{~mm}$ (approximately $3 \mathrm{~mm}$ day $^{-1}$ during linear growth and $1.5 \mathrm{~mm}$ day ${ }^{-1}$ during regression) (Ginther, 1986; Palmer, 1987). The differences between studies may represent, at least in part, the sequential measurement of individual follicles in previous studies versus the use of daily mean diameters in the present study. For example, the presence of a regressing follicle would lower the mean growth rates.

The analyses of tiers 2-5 in individual mares suggested that wave-like activity occurred that was not always synchronized with the primary wave detected in tier 1 . However, unlike the follicles of tier 1 , an increase followed by a decrease in mean diameters in each of tiers $2-5$ could potentially result by movement (growth or regression) of individual follicles from one tier to another as well as by growth and regression within a tier. Reservation must therefore be maintained in the interpretation of the apparent wave-like activity detected in tiers $2-5$ of individual mares. The presence of underlying waves suggested that growth and regression of small follicles occurred throughout the interovulatory interval. The underlying waves were more common in the tiers with the smaller follicles, suggesting that the smaller follicles were more likely to undergo atresia after a short period of growth than were the larger follicles represented by the upper tiers.

Seven mares demonstrated underlying follicular waves during the interval between ovulation and emergence of the primary wave, whereas eight did not. Presumably the manifestation of underlying waves would have depended on the day-to-day proportionality of the regressing follicles of a previous wave versus the growing follicles of a new wave. The mares with underlying waves had more follicles $>5 \mathrm{~mm}$ and a larger mean diameter of tier 1 follicles on the day of emergence of the primary wave. These findings suggest that larger diameters and a greater proportion of growing versus regressing follicles favoured the statistical identification of underlying waves between the day of ovulation and day of emergence of the primary wave. When all follicular tiers were considered, approximately four waves occurred per interovulatory interval. When luteolysis occurred during an interwave interval, the interval was twice as long as for other interwave intervals. Prolonged interwave intervals associated with luteolysis also seemed temporally related to a plateau in growth of the tier 1 follicles; only the selected or dominant follicle continued to grow after this time.

When data within each tier were normalized to the mean day of emergence of the primary waves (composite data), the resulting mean follicular profiles for tiers 1-5 were approximately parallel. That is, the mean diameters for the tiers initially decreased and then on a mean of 6 days after ovulation, the 
mean diameters began to increase. Our interpretation is that the mean significant decrease in diameters for each tier before the day of wave emergence was the result of regression of the majority of follicles of the various diameters represented by each tier during this time. That is, sufficient follicles were regressing to cause a significant decrease, despite the likely presence of some growing follicles (discussed below). The mean day of emergence of the primary wave was synchronized with the day of emergence of the waves detected in each of tiers 2-5. These composite results indicated that, on average, diameters of growing follicles ranging from 3 to $12 \mathrm{~mm}$ (mean diameters 6 days after ovulation for tiers $1-5$ ) began to exceed the diameters of regressing follicles on the day defined as the day of wave emergence. It is reasonable that the follicles of the upper tier that emerged 6 days after ovulation would have begun as 3-4 mm follicles several days before emergence of a wave. If the rate of growth before emergence was similar to the rate of growth after emergence $\left(1 \mathrm{~mm}\right.$ day $\left.{ }^{-1}\right)$, the follicles that emerged 6 days after ovulation in tier 1 (mean diameter, $12 \mathrm{~mm}$ ) would have been $3 \mathrm{~mm} 3$ days before ovulation. This interpretation is compatible with several reports that FSH concentrations on average begin to increase a few days before ovulation (for review see Ginther, 1992). The growing follicles between the day of ovulation and the day of wave emergence would have been masked in the statistical analyses by a larger number of regressing follicles during this time.

After the day of wave emergence, the average number of follicles of each composite tier increased in diameter, indicating, by interpretation, that the number of growing follicles now exceeded the number or regressing follicles of a corresponding diameter. The increasing diameters of follicles of tier 1 reached a maximum mean 9 days after emergence (equivalent to 15 days after ovulation). This finding can be taken as an indication of the day of divergence when the dominant follicle continues to grow and the remaining follicles begin to regress; this phenomenon (divergence or dissociation) has been described in several reports (for review see Ginther, 1992). The postulated mixture of growing and regressing follicles after emergence of the primary wave is consistent with the following results of a limited histological study (Driancourt et al., 1982) in ponies: (1) normal follicles were larger and number of atretic follicles was reduced 14 days after ovulation compared with 6 days and (2) normal follicles were larger and the percentage of atretic follicles was greater 17 days after ovulation than on 14 days after ovulation. In conclusion, the composite data can be interpreted on the basis of changing ratios of growing to regressing follicles. Follicles as small as $3 \mathrm{~mm}$ were growing during the period extending from a few days before ovulation until at least the day of emergence of the primary wave. Follicles of various diameters were undergoing growth during the entire period from ovulation until at least the day of divergence into dominant and subordinate follicles.

Pulses of FSH concentrations have been detected in equine blood samples collected frequently within $24 \mathrm{~h}$ on discrete days of the oestrous cycle (Alexander et al., 1987; Thompson et al., 1987; Evans, 1990). In one study (Thompson et al., 1987), the interval between pulses was significantly shorter during the mid- to late-luteal phase $\left(5\right.$ pulses $h^{-1}$ ) than during oestrus ( 3 pulses $\mathrm{h}^{-1}$ ). In the present study, only one blood sample was available for each day. Presumably, the daily concentrations were influenced by the portion of a pulse that was sampled and by accumulative levels or changes in pulse characteristics. It was not clear whether daily samples were representative. Nevertheless, the daily FSH means reported herein could be interpreted in terms of follicular events. In the composite data (data normalized to the mean day of emergence of the primary wave), the FSH concentrations were highest for the day before, on and after emergence of the single wave encompassing all tiers. Although the nature of FSH pulses was unknown, it seems reasonable to conclude that the follicles were, on average, exposed to more FSH during the time of high mean FSH concentrations. Similarly, the smallest follicles detected $(2-3 \mathrm{~mm})$ responded to increasing exposure to $\mathrm{FSH}$ as suggested by the following results: (1) the tier with the smallest follicles (tier 5) in the composite data showed wave emergence on the days with the highest FSH concentrations, as did all tiers; and (2) the frequent (significant) association between an increase in number of $2-3 \mathrm{~mm}$ follicles and an increase in FSH concentrations. The latter finding was from an analysis that did not involve grouping the follicles into tiers.

In conclusion, the results demonstrated that the net effect of folliculogenesis, as shown by the composite data, was that the diameters of growing follicles began, on average, to exceed diameters of regressing follicles on a mean of 6 days after ovulation for all tiers (follicles averaging 3-12 mm). This common day of wave emergence was temporally associated with the highest mean FSH concentrations of the oestrous cycle. Results also tentatively suggested the following: (1) follicles that emerged as part of the primary wave at approximately $12 \mathrm{~mm}$ began to exceed $2-3 \mathrm{~mm}$ a few days before ovulation; (2) the incidence of underlying waves was greatest in the tiers consisting of the smallest follicles, possibly due to a shorter viable life span for many of the smaller follicles and (3) the numbers and diameters of $2-3 \mathrm{~mm}$ follicles increased in temporal association with increased exposure to FSH.

This work was supported by the College of Agricultural and Life Sciences, University of Wisconsin-Madison and by Equiculture, Inc., Cross Plains, Wisconsin. The authors thank R. A. Pierson for data collection, L. Kulick for graphics and computer assistance, and M. Radtke for manuscript preparation.

\section{References}

Alexander SL, Irvine CHG and Turner JE (1987) Comparison by three different radioimmunoassay systems of the polymorphism of plasma FSH in mares in various reproductive states Journal of Reproduction and Fertility Supplement 35 9-18

Bergfelt DR and Ginther OJ (1993) Relationships between FSH surges and follicular waves during the estrous cycle in mares Theriogenology 39, 781-796

Driancourt MA, Mariana JC and Palmer E (1982) Effect of the stage of the oestrous cycle on the follicular population in pony mares Reproduction Nutrition Développement 22 803-812

Evans JW (1990) FSH secretion patterns in cycling mares: ultradian rhythms Joumal of Equine Veterinary Science 10 203-207

Freedman LJ, Garcia MC and Ginther OJ (1979) Influence of photoperiod and ovaries on seasonal reproductive activity in mares Biology of Reproduction 20 $567-574$

Ginther OJ (1986) Ultrasonic Imaging and Reproductive Events in the Mare Equiservices Inc., Wisconsin 
Ginther OJ (1990) Folliculogenesis during the transitional period and early ovulatory season in mares Journal of Reproduction and Fertility 90 311-320

Ginther OJ (1992) Reproductive Biology of the Mare: Basic and Applied Aspects (2nd Edn) Equiservices, Inc., Wisconsin

Ginther OJ (1993) Major and minor follicular waves during the equine estrous cycle Journal of Equine Veterinary Science 13 17-24

Ginther OJ and Bergfelt DR (1992) Ultrasonic characterization of follicular waves in mares without maintaining identity of individual follicles jourmal of Equine Veterinary Science 12 349-354

Palmer E (1987) New results on follicular growth and ovulation in the mare. In Follicular Growth and Ovulation Rate in Farm Animals pp 237-255 Eds JF Roche and D O'Callaghan. Martinus Nijhoff Publishers, New York
Pierson RA and Ginther OJ (1987) Follicular population dynamics during the estrous cycle of the mare Animal Reproduction Science 14 219-231

Pineda MH, Garcia MR and Ginther OJ (1973) Effect of antiserum against an equine pituitary fraction on the corpus luteum and follicles in mares during diestrus American Journal of Veterinary Research 34 181-183

Sirois J, Ball BA and Fortune JE (1989) Patterns of growth and regression of ovarian follicles during the oestrous cycle and after hemiovariectomy in mares Equine Veterinary Journal 8 (Supplement) 43-49

Thompson DL, McNeill DR, Wiest JJ, St George RL, Jones LS and Garza F (1987) Secretion of luteinizing hormone and follicle stimulating hormone in intact and ovariectomized mares in summer and winter Journal of Animal Science 64 247-253 